\title{
Direito à saúde, atenção básica e transferências condicionadas de renda na América Latina
}

\author{
H ealthcare rights and conditional cash transfers in Latin America
}

Ana M aria M edeiros da Fonseca ${ }^{1}$

Ana Luiza d'Ávila Viana ${ }^{2}$

${ }^{1} \mathrm{Nú}$ cleo deEstudosem

Políticas Públicas

Universidade Estadual de

Campinas. Av. Albert

Einstein 1300, Cidade

Universitária. 13081-970

Campinas SP.

anafon@uol.com.br

${ }^{2}$ Departamento deM edicina

Preventiva, Faculdade de

M edicina, U niversidade de

São Paulo.

Abstract Conditional cash transfer programs in Latin America impose specific requirements and responsibilities on beneficiary households, in order to upgrade education levels, improve dropout ratesand eliminate child labor, while enhancing health and nutrition indicators. Although counterpart healthcare conditions are common to all these programs, government strategies differ in terms of reaching their goals, at times even undermining improvements in the living conditions of more vulnerable segments of the population. Instead of upholding rights to healthcare, such initiatives may well trigger a new cycle of tightly-focused basic care through provisional programs.

Key words Conditional cash transfer programs, Right to healthcare
Resumo Os programas de transferência de renda na América Latina foram acompanhados de condicionalidades - responsabilidades com o objetivo de melhorar os níveis educacionais, impedir a evasão escolar e o trabalho infantil e também para melhorar os indicadores de saúde e nutrição. A pesar da relativa uniformidade encontrada na condicionalidade vinculada à saúde, as estratégias utilizadas pelos governos para cumprir com as metas e os objetivos estabel ecidos são diversas e configuram dificuldadesadicionais para a melhoria das condições de vida das populações mais vulneráveis. Longe de essa iniciativa incentivar o direito à saúde, talvez o que promova seja expansão de um novo ciclo de programas de atenção básica focalizados e de natureza provisória.

Palavras-chave Programas detranferência condicionada de renda, Direito à saúde 
Introdução

0 objetivo desse artigo é realizar uma reflexão acerca da relação entre direito à saúde e transferência condicionada de renda, identificando diferentes estratégias adotadas pelos países para cumprir com as condicionalidades definidas para área da saúde.

Para melhor entender os programas detransferência de renda e as dificuldades encontradas, iniciamos por um breve histórico do modelo de proteção social na América Latina e Caribe. Esta é maneira de sublinhar o contexto em que surgem os programas.

Na segunda parte, fazemos uma descrição dos programas para destacar as inovações por eles introduzidas, seus critérios de seleção e funcionamento e, ainda, deixar evidente que a sua disseminação não obedece a um espectro político específico, como poderia se supor.

No terceiro item, sintetizamos os elementos que os programas têm em comum e destacamos as soluções encontradas pelo Estado para que as condicional idades referentes à saúde sejam cumpridas e os limites do "direito à saúde" a partir dessa estratégia.

\section{Proteção social: América Latina eCaribe}

O modelo de proteção social na América Latina e no Caribe foi baseado no emprego formal e garantia dois tipos básicos de prestações: (a) assistência à saúde, individual e curativa; (b) aposentadorias, pensões e benefícios por acidentes de trabalho. Este modelo de proteção se expandiu da década de 30 até meados dos anos 70 do século passado. 0 modelo é protetor, embora não redistributivo, pois mantém as posições do mercado de trabal ho, isto é, as desigualdades produzi das pela sociedade salarial, ou melhor, a hierarquia salarial.

A crise econômica dos dois últimos decênios do século XX contribuiu para a deterioração dos seguros sociais - trabalhadores perdem seus postos de trabalho, o mercado de trabalho encolhe e o Estado se retrai. Finalmente, os programas de ajuste estrutural, que tiveram início na região, provocaram severos custos sociais e agravaram a crise do modelo de proteção do tipo seguro social. A antiga assistência social, limitada a poucos países da região e com recursos escassos, foi afetada pela dupla crise ${ }^{1}$.

Cabe assinalar que a questão de modelos universais não esteve colocada para a América
Latina e o Caribe, embora no Brasil o tema tenha estado presente em um momento especial nos anos 80: redemocratização com questionamento do antigo modelo de proteção social. Assim, a Constituição de 1988 aprovou o principio da seguridadesocial, envolvendo previdência social, saúde e assistência social, porém sem uma estrutura ministerial única.

$N$ a nossa região, a estratégia para sair da crise recorreu a um duplo movimento: (a) medidas de privatização de empresas e serviços públicos, abertura comercial, incremento deimpostoscom a finalidade de reduzir o déficit fiscal e realizar superávit, etc.; (b) reformas na proteção social com fortes críticas a seu funcionamento - ineficiência administrativa, desequilíbrio financeiro, exclusão dos mais pobres, etc.

A crise econômica e os programas de ajuste agravaram a pobreza e foi neste contexto que surgiram na América Latina e Caribe as redes de proteção social destinadas à focalização nos grupos mais vulneráveis. Foi também neste contexto ena metade dos anos 90 que tiveram início os primeiros programas de transferências monetárias condicionadas. Em resumo, reforma nos model os deseguro, redes de proteção com transferência monetária condicionada para os mais pobres ${ }^{1}$.

\section{Os programas na América Latina e Caribe}

Na região, os programas (Quadro 1) foram apresentados como uma inovação por romperem com a tradição das cestas básicas e por realizarem transferências monetárias sem 0 requisito de prévia contribuição, como no modelo seguro social. Finalmente, eles foram considerados singulares por estabelecerem co-responsabilidades com o objetivo de melhorar os níveis educacionais, impedir a evasão escolar eo trabal ho infantil e, ainda, melhorar os indicadores de saúde e nutrição. A idéia central é que os programas asseguram o exercício, mesmo quetemporário, de três direitos: educação, saúde e alimentação.

A despeito das diferenças entre os programas - condições de acesso, do valor do beneficio e da sua fórmula de cálculo, do tempo de permanência previsto, dos model os de acompanhamento, dos sistemas de seleção e identificação, das relações entre os níveis degoverno na gestão do programa, das modalidades de financiamento - eles têm em comum, pelo menos, três elementos: 0 foco em famílias, pobres ou extremamente pobres, com crianças e adolescentes (com algumas 
exceções como o programa do Uruguai, por exemplo, queémais amplo); o principio das contrapartidas ou condicionalidades e o não pertencimento ao campo dos direitos².

Em 1997, no M éxico, o PRO GRESA (Programa de Educação, SaúdeeAlimentação), antecessor do programa Oportunidades, foi concebido demaneiraintersetorial ecomo um meio deacesso aos direitos à saúde, a educação básica e à alimentação adequada.

0 Oportunidades, como um programa com co-responsabilidade, estabelece o quesegue: apoios monetários (para a alimentação e educação) condicionados à freqüência escolar das crianças eadolescentes e dos membros da família aos serviços desaúde. 0 M éxico, porém, ampliou o público alvo do programa pela incorporação dos idosos (70 ou mais anos) que recebem o valor equivalente a 25 dólares e devem comparecer a oito visitas médicas programadas ao centro de saúde ${ }^{3}$.

No caso do Brasil, os programas começaram por iniciativa dos governos munici pais e estaduais, ainda em 1995, e o governo federal seguiu pela trilha aberta pelas instâncias subnacionais. Em 1998, porém, o governo federal, por meio da legislação que autorizou a concessão de recursos financeiros aos municípios (com certos critérios técnicos) que quisessem implantar pro- gramas de renda mínima associada à educação e não dispusessem de recursos, deu início a uma iniciativa de certa envergadura. 0 projeto, no entanto, foi abandonado ea partir da metade do segundo governo do presidente $\mathrm{FHC}$ teve lugar uma etapa de criação de programas em ministérios setoriais: Bolsa Escola (MEC), Bolsa Alimentação (MS), Auxílio Gás (M ME) e Bolsa Renda para as situações de emergência (secas e inundações) nas áreas rurais.

O governo Lula, por sua vez, instituiu o Cartão Alimentação (MESA) como um acréscimo de renda aos beneficiários dos demais programas com ênfase na região do semi-árido. 0 programa era um dos componentes da política denominada Fome Zero. Estes programas foram unificados em outubro de 2003, dando origem ao programa Bolsa Família, que é um programa de transferência monetária com condicionalidades: saúde e educação.

É importante registrar, entretanto, que na América Latina e Caribe apenas o Brasil, Costa Rica e Cuba são países nos quais a saúde é um direito universal. Para os dois últimos, não há registro de programas de transferência de renda, embora a Costa Rica esteja discutindo a implementação de um programa destinado aos jovens que funcionasse com um duplo objetivo: estímulo à conclusão do ensino médio e redução da

Quadro 1. Programas na América Latina e Caribe.

\begin{tabular}{|l|l|l|}
\hline \multicolumn{1}{|c|}{ Países } & Ano & \multicolumn{1}{c|}{ Nome } \\
\hline M éxico & 1997 & Progresa-O portunidades \\
\hline Brasil & 1997 & $\begin{array}{l}\text { PGRM; Bolsa Escola (2001); Bolsa Alimentação (2001); Auxilio } \\
\text { Gás (2002); Cartão Alimentação (2003); Bolsa Família (2003). }\end{array}$ \\
\hline Nicarágua & 2000 & Mi Família \\
\hline Colômbia & 2001 & Famílias en Acción \\
\hline Equador & 2001 & Bono Solidaridad-Bono de Desarrollo Solidario \\
\hline Argentina & 2002 & Jefes y Jefas de Familia \\
\hline Chile & 2002 & Chile Solidário \\
\hline El Salvador & 2005 & Programa Oportunidades (Red de Protección Social) \\
\hline Uruguai & 2005 & Ingreso Ciudadano \\
\hline Paraguai & 2005 & Tekoporã; Ñopytyvo (na região do Chaco) \\
\hline R. Dominicana & 2005 & Solidaridad \\
\hline Peru & 2005 & Juntos \\
\hline Panamá & 2006 & Red de O portunidades \\
\hline
\end{tabular}


pressão sob o mercado de trabal ho. No caso do Brasil, a condicionalidade para a área de saúde tem o objetivo de estimular as famílias a manter atualizado o calendário e vacinação das crianças atésete anos de idade, levá-las para pesar emedir conforme o calendário da saúde. Já para as gestantes e nutrizes, as condicionalidades são: realizar o pré natal; seguir com o acompanhamento após o parto e participar das atividades educativas desenvolvidas pelas equipes de saúde sobre al eitamento materno e alimentação saudável.

Na N icarágua, o Programa M i Família, que pertence à Rede de Proteção Social, como os demais programas na região, tem como objetivos: melhorar a alimentação das famílias em situação de extrema pobreza; reduzir o absenteísmo escolar; aumentar os cuidados de saúde das crianças e adolescentes.

$\mathrm{Na}$ Colômbia, o programa Famílias em Ação é dirigido às famílias em situação de extrema pobreza com crianças e adolescentes. 0 programa apresenta al gumas semelhanças com o mexicano: os componentes de educação, saúde e alimentação. Do mesmo modo que os demais programas, Famílias em Ação é um programa de transferência monetária com co-responsabilidades. Assim, para o ben efício nutricional, asfamílias devem manter em dia a carteira de vacina de seus filhos/as; levar as crianças menores de sete anos para os exames de controle do crescimento e desenvolvimento (peso ealtura). Para o subsídio escolar, devem garantir queas crianças eadolescentes não faltem às aulas de forma injustificável (mais de oito vezes no bimestre) ${ }^{4}$.

No Chile, o projeto piloto Chile Solidário, após um ano e meio de debate, foi convertido em Lei em 2004. Em 2002, o então Presidente Ricardo Lagos afirmou que o desafio de seu governo consistia em eliminar a indigência até 0 final de seu governo (2005). Este desafio conduziu à criação do Sistema Chile Solidário e do programa Puente - mecanismo de trabal ho com as famílias - edo Fundo de Solidariedade e Inversão (FOSIS) como meio de financiamento do sistema.

0 programa se dirige às famílias em situação de indigência e conta com quatro componentes: 1) apoio psicossocial (Programa Puente/FOSIS); 2) apoio econômico mensal de proteção à família (cerca de 15 dólares nos primeiros seis meses, 11,5 dólares do 70 ao 120 mês ede 8 e 5 dólares no segundo ano; 3) outros benefícios monetários garantidos - pensões por velhice, invalidez, deficiência mental, etc. 4) acesso preferencial aosprogramas de promoção social.

No Equador, em 2001, o governo tentou eli- minar o subsídio universal ao gás e outorgar uma transferência monetária aos extremamente pobres por meio de um programa denominado Bônus de Solidariedade. 0 subsídio ao gás, porém, voltou a ser concedido, mas o Bônus foi mantido. Em 2002, foi instituído o Bônus de Desenvolvimento Humano. O programa paga 15 dólares mensais por família e, do mesmo modo que os demais programas na região, é um programa de transferência monetária condicionada: saúde - para as famílias com crianças menores de 5 anos e mulheres grávidas; educação para as crianças e adolescentes (6 a 15 anos) com a condição de freqüência escolar de $90 \%{ }^{5}$.

$\mathrm{N}$ a República D ominicana, o Programa Solidariedade, lançado em 2005 eque pertenceà Rede de Proteção Social, opera com três componentes: Comer éPrimeiro - em torno de 17 dólarespara alimentação; Incentivo à Freqüência - 4,5 dólares por criança eadolescente em idade escolar (entre 6 e 16 anos) e até quatro por família; e República Dominicana com Nomee Sobrenome (documentação civil). Solidariedade se dirige às famílias em situação de extrema pobreza e de modo inovador admite, no programa Comer é Primeiro, famílias sem filhos/as em idade escolar. Neste sentido, tem um ponto em comum com - Programa Renda Cidadã (Ingreso Ciudadano) do Uruguai, que teve início em 2005.

No Paraguai, o programa Tekoporã (bemestar em guarani) se dirige às famílias em situação de extrema pobreza que residem nas zonas rurais e têm crianças e adolescentes. Lançado em 2005, o programa, que pertenceà Redede Proteção Social, opera com condicionalidades vinculadas à saúde (vacinas, peso e altura das crianças e acompanhamento das mulheres grávidas) e à educação: freqüência escolar. Demodo semel hante ao programa do Chile, conta com os chamados Guias Familiares que fazem o acompanhamento das famílias.

$\mathrm{Na}$ Argentina, o programa Jefes y Jefas del Hogar, lançado oficialmente em 2002, destinava-se aos chefes de família sem emprego, com filhos/as até 18 anos de idade ou incapacitados (de qualquer idade) ou, ainda com o/a chefe ou cônjuge grávida. 0 programa consistia em um benefício monetário no valor de 50 dólares ( 150 pesos) com uma dupla condição: crianças e adolescentes nas escolas; participação em atividades de melhorias nas comunidades e que funcionassem como capacitação. O M inistério do Desenvolvimento Social e M eio Ambiente é a instituição responsável pelo programa.

Em fevereiro de 2006, foi anunciada a refor- 
mulação do Programa ou sua substituição por três outros: Familias para la Inclusión Social, Seguro de Empleo y Capacitación e Seguro de Desempleo.

De maneira distinta do programa Jefes y Jefas del Hogar, Familias para la Inclusión retira as contraprestações de trabal ho e mantém os compromissos com educação e saúde e já não é exclusivamente para os chefes de família desempregados.

No Peru, o Programa Juntos, lançado em setembro de 2005, se dirige às famílias pobres com crianças e adolescentes. As famílias recebem um valor fixo (30 dólares) como incentivo ao cumprimento dos compromissos de participação em alguns programas das áreas de saúde (vacinas, peso e altura, acompanhamento pré natal), nutrição (complemento nutricional), educação (freqüência escolar) e cidadania (palestras, documentação civil).

Em El Salvador, começou em 2005, como parte da estratégia social para o período 20042009, o Programa Oportunidades com cinco componentes. 0 programa se dirige às famílias em situação de extrema pobreza e com crianças e adolescentes (menores de 15 anos) ou com muIheres grávidas no momento do cadastramento. 0 valor do benefício varia entre 15 e 20 dólares por família eo tempo máximo de permanência é de três anos. As co-responsabilidades são: saúde (pré-natal, controle do crescimento e desenvolvimento - peso ealtura, vacinação completa para os menores de cinco anos); educação: matrícula efreqüência escolar (crianças entre 5 e 15 anos) e capacitação quando ofertada.

No Panamá, o programa Rede de O portunidades começou em abril de 2006 e é como os demais programas na região, um programa de transferência monetária condicionada à educação (freqüência escolar) e aos controles de saúde do grupo materno infantil.

\section{Evidências edesafios}

Os programas compartem, conforme descrição no item anterior, al gumas características e entre estas a focalização - famílias pobres com crianças e adolescente -, a co-responsabilidade para os componentes de saúde e educação.

0 tema da focalização também é lido como eqüidade: os programas são dirigidos aos mais pobres e vulneráveis (desde quetenham crianças e adolescente) e por isto os sistemas de cadastramento e seleção adquirem grande importância.
As condicionalidades estabelecidas pelos programas são traduzidas por integralidade: ações coordenadas entre os distintos setores das políticas sociais para promover sinergias, enfrentar as características multidimensionais da pobreza e otimizar o gasto social. 0 não cumprimento injustificável das condicionalidades pode desembocar na suspensão do benefício eaté mesmo no cancelamento.

A condicionalidade, no entanto, também significa co-responsabilidade como compromisso de mão dupla. 0 Estado assume a oferta de serviços públicos e os beneficiários assumem seus compromissos nas áreas de educação e saúde, sobretudo, por meio por dos termos de compromissos (conhecimento das condições).

Finalmente, há dois outros componentes que todos os programas incorporam: (a) transparência - os controles sociais com a participação do Estado e de organizações da sociedade, as assembléias comunitárias de validação (Peru), os comitês de revisão (Paraguai) entre outros mecanismos; (b) avaliação - para medir os impactos nas condições de vida, as melhorias nos indicadores sociais, para realizar eventuais ajustes e para a prestação de conta do gasto público.

Os programas também colocam desafios à reflexão quando se pensa na saúde, mas também na educação, como direitos, pois a titularidade dos direitos é transitória: 0 acesso deriva da condição de pobreza e do vínculo com o programa de transferência de renda. 0 acesso é "garantido", na maior parte dos países, enquanto cada família permanecer no programa. Não há, portanto, a saúde como direito. No caso da saúde, se trata somente de atenção básica reduzida ao grupo materno infantil (imunizações, controle do crescimento edesenvolvimento eacompanhamento pré-natal). Este pacote, quando é garantido, não funciona como uma porta de entrada para outros níveis de atenção à saúde, ou seja, não opera como um filtro para selecionar os casos que requeiram cuidado especializado em outro nível de atenção. Por isso mesmo, é difícil, talvez impossível, estabelecer uma relação entre as condicionalidades dos programas para a área de saúde e o direito à saúde.

$\mathrm{Na}$ área da saúde, em algumas realidades nacionais, existe o risco do Estado assegurar tão somente serviços pobres esó para os pobres. Este aspecto não é trivial e na nossa região as autoridades de saúde mencionam como preocupação:

- A alta morbimortalidade materno infantil (Nicarágua, Peru, República Dominicana, Bolívia e Guatemala); 
- As enfermidades infecciosas de transmissão como malária, dengue, mal de Chagas, Leshmaniasis (Equador, El Salvador, Peru, Honduras) e ocupa o segundo lugar no Brasil, Guatemala e Nicarágua;

- As enfermidades crônico degenerativas como hipertensão e diabetes (Chile, Colômbia, Panamá) $)^{6}$.

Esse quadro indica que as condicionalidades, no caso da saúde, atacam somente parte dos problemas de saúde da região e somente para uma parte da população, o que talvez não auxilie a melhorar osindicadores desaúde como um todo, pois essa melhora depende de ações integrais de saúde- envolvendo todos os níveis do sistema de saúde - e não somente al gumas ações específicas.

Quanto ao tema da focalização e seletividade, tão caro aos programas, é importante registrar que em algumas experiências nacionais, os mais pobres que vivem em localidades onde não há oferta de serviços públicos não têm acesso ao programa (quando o critério de implantação passa pelo exame da oferta) e assim são duplamentepenalizados.

$\mathrm{Na}$ questão das co-responsabilidades, em tese 0 Estado entra com a oferta e o beneficiário exerce o seu direito e cumpre o seu dever. Há, então, pressão por oferta e se o Estado não cumpre com sua parte os objetivos do programa ficam comprometidos. De outro modo, se cumpre a sua parte, ampliando a oferta em determinados territórios (onde o programa está sendo implantado), acaba por afetar o direito de mobilidade das famílias, pois a oferta é localizada.

Na experiência recentedo Paraguai, por exemplo, com o apoio de uma instituição do governo alemão (GTZ), foi implantada uma farmácia básica (cem produtos vendidos quase a preço de custo) para que os beneficiários não usem parte do recurso com medicamentos ou não fiquem endividados nas farmácias ou ainda fiquem prisioneiros de favores. Esta experiência tem chamado a atenção em outros países que têm programas dirigidos aos mais pobres, mas os mesmos não têm acesso fácil a medicamentos.

Condicional idades e estratégias para superar deficiências estruturais

No campo da concertação, as atividades intersetoriais para ultrapassar uma área específica e promover sinergias são imprescindíveis. No caso da saúde, é necessário saneamento básico, abastecimento de água, cuidados com o meio ambi- ente (em um bom número de países, a lenha é o combustível para cozinhar e fumaça fica dentro das casas). Certamente, também é importante educação em saúde, nutrição (valor dos alimentos). Em resumo, algo mais que as imunizaçõese os cuidados do grupo materno infantil.

$\mathrm{N}$ a nossa região, nos anos 90 estava em voga um discurso sobre a tarefa de compensar as desigualdades por meio da criação de oportunidades: de acesso, especialmente à educação eá saúde e também às condições básicas de habitação. Estes propósitos guiariam as políticas sociais em boa parte dos países latino-americanos e com resultados de distinto alcance. Entretanto, a dependência dos direitos sociais à inserção no mercado formal de trabalho torna vulneráveis tais direitos para um amplo segmento da sociedadee os programas de transferência monetária não asseguram direitos ${ }^{7}$.

0 grande problema é a deficiência estrutural no que concerne ao investimento em serviços públicos de educação e saúde. A América Latina desde a crise dos anos 70 parou de crescer e investiu muito pouco na ampliação deescolas, equipamentos de saúde e no incentivo à expansão dos atendimentos de atenção básica integrados aos sistemas públicos de saúde.

Como vimos, os programas são fortemente voltados para atenção básica, restritos à área materno-infantil enão introduzem nenhum outro compromisso com a integralidade da saúde (atenção integral a todos os problemas e necessidades de saúde) e muito menos com a noção de direito à saúde.

Como as políticas de expansão da atenção básica nesses países estiveram restritas, principalmente pela ênfase dada às reformas estruturais voltadas para introdução de novos modelos de gestão, enxugamento dos custos, participação dos usuários no financiamento das ações de saúde, há imensas dificuldades no cumprimento com os requisitos de oferecer atenção básica, mesmo que restrita a apenas doisgrupos populacionais - mães e crianças. Por isso, os países esboçaram diferentes estratégias para poder cumprir com as metas desenhadas em relação à saúde.

Essas estratégias podem ser agrupadas em três diferentes saídas:

- transferir recursos para o orçamento da saúde (M S), de forma que o setor possa investir ecustear o aumento da demanda criada pelo programa, caso do Peru;

- implementar o programa somente nas áre as onde haja suficiente oferta, como ocorreu na Nicarágua e no Paraguai; 
- expandir a oferta pela compra de serviços privados de algumas $\mathrm{ONGs}$, como se deu em El Salvador.

Ambas as estratégias ou penalizam o programa, extraindo recursos, ou penalizam populações necessitadas, escolhendo áreas onde haja oferta de saúde, ou ainda, cumprem com as condicionalidades de forma pontual, quando resolvem comprar serviços para populações específicas. Em todos os casos, não há uma estratégia forte de enfrentamento da questão saúde introduzida pelos programas de transferência de renda. N esses casos, o que se vê não é nem uma perspectiva de expansão de cobertura, muito menos o desenvolvimento da atenção básica como previsto pela Conferência deAlma-Ata, isto é, integrada aos demais níveis do sistema e fator de integração entre a saúde coletiva e individual.

Dessa forma, 0 incentivo à expansão de cobertura de algumas ações de saúde formulado pelos programas pode se concretizar de forma bastante restrita e não conduzir a uma melhoria na oferta permanente de atenção básica, muito menos na integração de programas de atenção básica com o restante dos componentes do sistema de saúde.

A ausência nos anos mais recentes de vigorosos programas de Atenção Básica na América Latina e 0 abandono da idéia de sistemas nacionais integrados de saúde fazem com que o incentivo se traduza em saídas pontuais, pois o próprio setor saúde está hoje descolado do atendimento às populações mais pobres, tendo em vista as reformas privatizantes, isto é, voltadas para públicos com recursos e capazes de financiar totalmenteou em parte suas necessidades de saúde.

Os programas, longe de incentivarem o direito à saúde, são mecanismos isolados de cumprimento das metas estabelecidas, que podem aliviar a curto prazo algumas situações insatisfatórias, mas que dificilmente serão capazes de criar uma virtualidade intersetorial onde políticase programas são capazes de fomentar o desenvolvimento de outras políticas eo efeito sinérgico de ambas alterarem as condições de pobreza.

Para isso, seria necessário que os sistemas de saúde iniciassem reformas de peso no sentido de privilegiar a atenção básica, expandir a oferta de serviços públicos, promover a integração entres os diferentes níveis de assistência de forma a gerar a formação de sistemas integrados, e começassem a trabalhar com a idéia de saúde como direito, isto é, responsabilidade coletiva enão responsabilidade individual.

Os programas, embora procurem operar como uma política integrada, são bastante dependentes da constituição sistêmica da área de saúde e tal tarefa não pode ser atribuição de um ou outro programa, mas de uma política pública de saúde de grande porte.

M uito recentemente, teveinício o lançamento e a implementação de alguns novos programas de atenção básica na América Latina, com recursosinternacionais (como naArgentina, por exemplo) eépossível que a pressão exercida pelos programas de transferência de renda tenha contribuído de alguma forma para a formulação dessas iniciativas.

Observe-se ainda que o Brasil difere radicalmente desse cenário, por ter introduzido na segunda metade da década de 90 um vigoroso programa de atenção básica - o Programa de Saúde da Família - de forma integrada ao desenvolvimento de sistemas municipais de saúde. A implementação do programa no Brasil se inicia pelas áreas mais carentes do país ( pequenos municípios do nordeste brasileiro) e paulatinamente se expande para outras áreas, com destaque para os municípios das regiões metropolitanas, mais populosos e onde são enormes as carências sociais.

Esse aspecto talvez explique a rápida adoção e implementação do programa no Brasil, sem grandes traumas, tendo em vista o grande número de pessoas cobertas, o tamanho mesmo do programa, quando comparado ao de outros países da região. N esse momento, cabe ressaltar a necessidade de estudos mais aprofundados no Brasil sobre o processo de interação entre o Bolsa Família eo PSF eos problemas advindos quando essa interação não ocorre, isto é, quando o município não aderiu ao PSF ou sua cobertura é insignificante. 


\section{Colaboradores}

AM M Fonseca e AL d'Ávila Viana participaram igualmente de todas as etapas da elaboração do artigo.

\section{Referências}

1. M esa-Lago C. Desarrollo social, reforma del Estado y de la seguridad social, al umbral del siglo XXI. Washington, D.C.: BID, 2006.

2. Fonseca AM M. Programas de Transferencia de Ingresos en una perspectiva internacional: características y desafíos. In: Foro de Intercambio de Experiencias Latinoamericanas sobre Programas de Transferencia M onetaria Condicionada; 2006; El Salvador.

3. Gándara MCS. In: Foro de Intercambio de Experiencias Latinoamericanas sobre Programas de Transferencia M onetaria Condicionada; 2006; El Salvador.

4. Prada FS. In: Foro de Intercambio de Experiencias Latinoamericanas sobre Programas de Transferencia M onetaria Condicionada; 2006; El Salvador.
5. Lucio R. Tercer Encuentro de la Red de Monitoreo de Política Social. 2004 Noviembre Quito.

6. CEPAL. Políticas y programas de salud en América Latina. Problemas y propuestas. Serie Políticas Sociales, 114. Santiago: Diciembre, 2005

7. Hardy C. Sociedades latinoamericanas y políticas sociales. In: Hardy C, editor. Equidad y protección social. Desafíos de políticas sociales en América Latina. Santiago: LOM Ediciones/Fundación Chile 21; 2004. p. 270-271.

Artigo apresentado em 08/01/2007

Aprovado em 08/03/2007

Versão final apresentada em 09/05/2007 